\title{
Evidenciação dos custos ambientais nas empresas que compõem o Índice de Sustentabilidade Empresarial (ISE)
}

\author{
Environmental costs disclosure in the company formed the Sustainability Index (ISE)
}

\section{Julio Orestes da Silva}

Mestre em Ciências Contábeis pelo Programa de Pós-Graduação em Ciências Contábeis da

Universidade Regional de Blumenau (PPGCC/FURB)

Doutorando em Controladoria e Contabilidade pela FEA/USP

Endereço: Rua Antônio da Veiga, 140 - Sala D 202

Bairro Victor Konder - Caixa Postal 1507

CEP 89012-900 - Blumenau/SC - Brasil

E-mail: orestesj@gmail.com

Telefone: (47) 3321-0565

\section{Paulo Roberto da Cunha}

Doutor em Ciências Contábeis e Administração pelo

Programa de Pós-Graduação em Ciências Contábeis da

Universidade Regional de Blumenau (PPGCC/FURB)

Endereço: Rua Antônio da Veiga, 140 - Sala D 202

Bairro Victor Konder - Caixa Postal 1507

CEP 89012-900 - Blumenau/SC - Brasil

E-mail: pauloccsa@furb.br

Telefone: (47) 3321-0565

\section{Roberto Carlos Klann}

Doutor em Ciências Contábeis e Administração pelo Programa de Pós-Graduação em Ciências Contábeis da Universidade Regional de Blumenau (PPGCC/FURB)

Endereço: Rua Antônio da Veiga, 140 - Sala D 202

Bairro Victor Konder - Caixa Postal 1507

CEP 89012-900 - Blumenau/SC - Brasil

E-mail: klann@,furb.br

Telefone: (47) 3321-0565

\section{Jorge Eduardo Scarpin}

Doutor em Controladoria e Contabilidade pela FEA/USP

Professor do Programa de Pós-Graduação em Ciências Contábeis da

Universidade Regional de Blumenau (PPGCC/FURB)

Endereço: Rua Antônio da Veiga, 140 - Sala D 202

Bairro Victor Konder - Caixa Postal 1507

CEP 89012-900 - Blumenau/SC - Brasil

E-mail: jorgescarpin@furb.br

Telefone: (47) 3321-0565 


\title{
Resumo
}

O estudo objetiva identificar as informações relacionadas aos custos ambientais mais evidenciadas nos relatórios de administração e notas explicativas das empresas que compõe o Índice de Sustentabilidade Empresarial (ISE), segundo a categorização proposta por Rover, Borba e Borgert (2008). A pesquisa caracteriza-se como descritiva, com abordagem qualitativa dos dados, realizada por meio de pesquisa documental, aplicando análise de conteúdo. A amostra constitui-se das empresas que compõem o ISE 2009/2010 da Bovespa. Os resultados demonstram que mais de 50\% das empresas do ISE evidenciam no relatório de administração ou nas notas explicativas no mínimo uma das categorias analisadas. Constatou-se que as empresas evidenciaram 49 observações, que corresponde a 9\% do total possível de evidenciação dos custos ambientais com base no modelo proposto. Conclui-se que as informações dos custos ambientais mais evidenciadas referem-se aos "custos para controlar impactos ambientais".

Palavras-chave: Custos ambientais. Evidenciação. Índice de Sustentabilidade empresarial.

\begin{abstract}
The study aims to analyze the information related to environmental costs reported through management reports and explanations of the companies that make up the Corporate Sustainability Index (ISE), according to the categorization proposed by Rover, Borba and Borgert (2008). The research is characterized as descriptive, with a qualitative approach, carried out through desk research, using content analysis. The sample consisted of companies that make up the ISE of Bovespa 2009/2010. The results show that over $50 \%$ of companies in the ISE show in the management report or in the notes at least one of the categories analyzed. It was found that companies showed 49 observations, which corresponds to $9 \%$ of the total possible disclosure of environmental costs on the model proposed. We conclude that the information in the environmental costs highlighted refer to the "cost to control environmental impacts".
\end{abstract}

Keywords: Environmental costs. Disclosure. Sustainability Index.

\section{Introdução}

Nas últimas décadas, a degradação ambiental ganhou maior visibilidade, fazendo com que as empresas que utilizam recursos naturais e poluem o meio ambiente tomem atitudes quanto à preservação e recuperação ambiental (ROVER; BORBA; BORGERT, 2008). A contabilidade que é vislumbrada com uma das principais fontes de informação para a tomada de decisão, muitas vezes é responsável por evidenciar nas demonstrações financeiras alocação dos recursos e custos ambientais com a finalidade de proporcionar informação adequada aos usuários, para a tomada de decisão.

A evidenciação das informações ambientais tem por objetivo "identificar, mensurar e esclarecer os eventos e transações econômico-financeiros que estejam relacionados com a proteção, preservação, e recuperação ambiental, ocorridos em um determinado período, visando à evidenciação da situação patrimonial da entidade" (RIBEIRO, 2005, p.45). As atividades relacionadas a proteção, preservação, e recuperação ambiental, geram custos para as organizações.

Os custos referentes ao gerenciamento, de maneira responsável dos 
impactos no desenvolvimento da atividade empresarial no meio ambiente, são custos ambientais, decorrentes de alguma ação voluntária ou incorridos para atender os objetivos e exigências ambientais dos órgãos reguladores, reconhecidas no momento da identificação (BERGAMINI, 2000). Os custos ambientais são decorrentes da proteção ambiental, compostos por atividade de redução de poluição e resíduos, monitoração da avaliação ambiental, estas atividades vem crescendo com o aumento da regulamentação ambiental, e visível preocupação da sociedade.

Esta nova abordagem exigida no ambiente empresarial promove simultaneamente, a responsabilidade social, reduz o uso de recursos naturais, reduzindo consequentemente, os impactos negativos sobre o meio ambiente, preservando a integridade do planeta para as futuras gerações, sem deixar de lado a rentabilidade esperada pelo investidor (BOVESPA, 2009). Em meados de 2005 foi criado o índice de ações para servir de referência aos investidores socialmente responsáveis, surgindo assim o Índice de Sustentabilidade Empresarial (ISE) (BOVESPA, 2009). O índice tem como objetivo ser composto por empresas que se destacam em responsabilidade social, com sustentabilidade no longo prazo, ser um referencial do desempenho das ações desse tipo de empresa, ser percebido como tal pelo mercado (credibilidade), ser replicável, e estimular boas práticas por parte das demais.

Assim, este estudo aborda o tema custos ambientais nos relatórios das empresas do índice de Sustentabilidade Empresarial da Bolsa de Valores de São Paulo. A questão de pesquisa que norteia este estudo é: Quais as informações mais evidenciadas pelas empresas que compõem o Índice de Sustentabilidade Empresarial (ISE) relacionadas a custos ambientais?

Neste sentido, o objetivo da pesquisa consiste em identificar as informações relacionadas aos custos ambientais mais evidenciadas nos relatórios de administração e notas explicativas das empresas que compõe o Índice de Sustentabilidade Empresarial (ISE), segundo a categorização proposta por Rover, Borba e Borgert (2008).

Ben e Schneider (2007) apresentaram um ensaio teórico acerca da inserção dos custos ambientais na estruturação da contabilidade ambiental. Constataram que apesar da relevância destacada do tema e dos trabalhos já realizados, restou evidente a necessidade de incremento na realização de estudos abordando a análise dos custos ambientais e a sua inserção na contabilidade ambiental em empresas de diversos segmentos da economia brasileira. Portanto, a realização desta pesquisa contribui ao verificar a evidenciação dos custos ambientais na gestão ambientalmente responsável dos gastos ambientais das atividades empresariais.

O estudo foi estruturado em sete seções, iniciando com esta introdução. Em seguida apresenta-se a fundamentação teórica, que aborda custos ambientais, 
evidenciação de informações contábeis e o Indice de Sustentabilidade Empresarial. Na seqüência é apresentada a metodologia utilizada para a realização da pesquisa. Após, é feita a análise dos dados, por último as considerações finais da pesquisa.

\section{Custos Ambientais}

Custos ambientais são representados por todos os custos dos recursos utilizados pelas atividades desenvolvidas com a finalidade de controle, preservação e recuperação ambiental (RIBEIRO, 1998). Custos ambientais compreendem os gastos referentes ao gerenciamento de maneira responsável dos impactos no desenvolvimento da atividade empresarial no meio ambiente. Ou seja, qualquer custo decorrente de alguma ação voluntária ou incorrido para atender os objetivos e exigências ambientais dos órgãos reguladores, reconhecidas no momento da identificação (BERGAMINI, 2000).

Tinoco e Kraemer (2004) mencionam que os custos ambientais são decorrentes da proteção ambiental, compostos por atividade de redução de poluição e resíduos, monitoração da avaliação ambiental, estas atividades vem crescendo com o aumento da regulamentação ambiental, e visível preocupação da sociedade. A preocupação com as questões ambientais faz com que os pesquisadores preocupem-se com o estudo dos custos ambientais, podendo destacar alguns estudos relevantes.

Gadenne e Zaman (2001) objetivaram verificar a associação entre o gerenciamento ambiental e as práticas contábeis, por meio de um questionário enviado a empresas australianas dos setores de química, mineração, óleo e gás e papel e celulose. Os resultados demonstram que muitas companhias ainda não desenvolveram o enfoque de custos ambientais e o gerenciamento destes. Esses autores concluem que apesar de grandes companhias como Western Mining e BHP incluírem os custos sociais e ambientais de suas atividades em seus relatórios financeiros, a grande maioria das companhias australianas não divulga esse tipo de informação, principalmente pelo fato de a divulgação ser predominantemente voluntária.

Burnett e Hansen (2008) realizaram um estudo sobre ecoeficiência, cujo objetivo foi investigar o relacionamento entre o desempenho ambiental e a eficiência produtiva nas indústrias do setor elétrico dos Estados Unidos da América, antes e depois das alterações na legislação sobre limpeza do ar de 1990. Utilizando o Data Envelopment Analysis (DEA), os exames cross-sectional revelaram que plantas industriais menos poluentes são mais eficientes do que plantas industriais mais poluentes. As análises longitudinais realizadas por esses autores indicaram que as empresas podem simultaneamente reduzir a poluição e aumentar a eficiência 
relativa. Esses autores concluem que o gerenciamento ambiental pró-ativo pode reduzir os custos ambientais e então, dar apoio para a adoção de um sistema de gerenciamento de custo ambiental.

$\mathrm{Lu}$ (2009) avaliou os custos ambientais de passageiros de companhias aéreas. Esse autor destaca que várias medidas ambientais têm sido utilizadas nos aeroportos para reduzir os impactos relacionados ao barulho das aeronaves, bem como suas emissões de gases. Esses custos ambientais e externalidades sociais devem ser internalizados e pagos pela indústria de aviação e por seus usuários. O estudo de Lu (2009) teve como objetivo investigar o impacto dos custos ambientais, por meio de taxas ambientais, na demanda de passageiros de diferentes modelos de linhas aéreas. O estudo analisou seis rotas entre dois pares de cidades, Londres-Amsterdã e Londres-Paris. As taxas ambientais foram então hipoteticamente aplicadas para dois modelos de negócios aéreos, operadoras de serviço completo (British Airways e Air France-KLM) e linhas aéreas de baixo custo (Easyjet). Os resultados deste estudo mostraram que a potencial redução na demanda de passageiros seria maior para o mercado Easyjet, embora com menos custo ambiental por passageiro.

Villiers e Van Staden (2010) pesquisaram acionistas individuais de três países, Austrália, Reino Unido e Estados Unidos da América, a respeito das evidenciações ambientais corporativas. Em geral, os pesquisados se mostraram interessados e positivamente associados a esse tipo de evidenciação. Eles solicitam, de maneira geral, informações sobre uma visão geral dos riscos e impactos ambientais, políticas ambientais, desempenho em relação a metas ambientais mensuráveis e informações sobre uma série de custos ambientais. A maior parte dos acionistas requer que as informações ambientais sejam auditadas. Eles acreditam que os gestores devam lhe prestar contas sobre os impactos ambientais de suas companhias.

Raiborn, Butler e Massoud (2011) afirmam que o sistema de informações contábeis tem falhado em evidenciar os custos ambientais, embora os gestores e demais stakeholders reconheçam a importância dos impactos ambientais das operações da firma na determinação de riscos e projeção de lucros futuros. $\mathrm{O}$ impacto negativo das operações da empresa sobre o ambiente pode ser visto como uma falha, da mesma forma que a fabricação de um produto com defeito pode ser visto como uma falha do controle de produção. Os autores afirmam ainda que custos são incorridos para prevenir e detectar falhas ambientais, e o custo da falha, especialmente se ele não está sendo monitorado pela empresa, pode ser grande e desconhecido. A partir disso, esses autores apresentam um modelo de evidenciação de custo ambiental, a fim de proporcionar maior transparência sobre o impacto ambiental dos negócios para gestores e outros interessados.

Quanto aos estudos no Brasil, Ben e Schneider (2007) realizaram um ensaio 
teórico acerca da contabilidade em empresas brasileiras, apresentando a inserção dos custos ambientais na estruturação da contabilidade ambiental. Constataram que apesar da relevância destacada do tema e dos trabalhos já realizados, restou evidente a necessidade de incremento na realização de estudos abordando a análise dos custos ambientais e a sua inserção na contabilidade ambiental em empresas de diversos segmentos da economia brasileira. Com relação à mensuração dos custos ambientais, observaram apenas poucos estudos nesse âmbito. Entretanto, o entendimento de tais custos por parte das empresas e o relacionamento dos mesmos com os fatores de produção podem proporcionar valiosas contribuições à empresa, racionalizando a utilização dos insumos utilizados na execução das atividades desenvolvidas que possuam relação com a proteção ao meio ambiente.

Rover, Borba e Borgert (2008) objetivaram identificar as informações sobre custos e investimentos ambientais e como são evidenciadas nas empresas classificadas no Índice de Sustentabilidade Empresarial de 2006/2007. Para tanto, utilizaram as demonstrações referentes ao ano de 2006. Os resultados revelaram que 13 empresas (38\%) evidenciaram informações referentes a custos ambientais, as categorias referentes a custos correspondentes a danos ambientais e a investimentos com projetos ou programas ambientais foram as mais evidenciadas nos relatórios investigados. Destacaram ainda que o tipo de evidenciação quantitativa monetária foi o mais utilizado, tanto nos custos como nos investimentos ambientais.

O presente estudo utilizou as mesmas categorias propostas por Rover, Borba e Borgert (2008), aplicadas às empresas que fazem parte do Índice de Sustentabilidade Empresarial de 2009/2010, utilizando-se relatórios de exercício de 2008.

\section{Evidenciação de Informações Ambientais}

Souza e Ribeiro (2004) destacam que elaboração e fornecimento de informações aos usuários internos e externos fazem parte dos objetivos da contabilidade, assim evidenciar as atividades da empresa com relação ao meio ambiente podem fornecer informações úteis a alguns investidores e essas evidenciações podem causar modificações na situação patrimonial da entidade.

O objetivo da evidenciação das informações ambientais é "identificar, mensurar e esclarecer os eventos e transações econômico-financeiros que estejam relacionados com a proteção, preservação, e recuperação ambiental, ocorridos em um determinado período, visando à evidenciação da situação patrimonial da entidade" (RIBEIRO, 2005, p.45). Entretanto, como afirma o Calixto (2006) às empresas que exercem atividades potencialmente poluidoras, naturalmente devem destacar as contas que se referem aos seus custos ambientais. 
A Evidenciação de informações ambientais atinge grandes proporções na atualidade, pois a humanidade preocupa-se cada vez mais com o desenvolvimento sustentável e a preservação ambiental. Na literatura acadêmica, tem-se debatido o tema de evidenciação ambiental, procurando observar a relevância do tema nos relatórios apresentados pelas empresas. Nesse sentido, destacam-se alguns estudos anteriores realizados sobre o tema.

Borba e Nazário (2003) objetivaram identificar como as empresas divulgam contabilmente informações sobre o meio ambiente. Os autores examinaram os relatórios contábeis de 37 companhias brasileiras de 10 setores potencialmente poluidores, classificadas entre as maiores e melhores, conforme a publicação da revista Exame do ano 2002. Concluíram que as referências à questão ambiental são encontradas principalmente no relatório da administração e em menor escala, nas notas explicativas e empresas do setor de siderurgia e metalurgia foram as únicas que destacaram suas provisões ambientais no balanço patrimonial.

Campbell (2004) analisou a quantidade de informações voluntárias divulgadas sobre meio ambiente, em empresas britânicas no período de 1974 a 2000. Os resultados do estudo demonstraram que ocorreu um aumento na divulgação de informações ambientais das empresas analisadas, principalmente a partir da década de 1980.

Azevedo e Cruz (2007) investigaram o nível de evidenciação das informações de natureza sócio-ambiental divulgadas pelas distribuidoras de energia elétrica que atuam na região Nordeste do Brasil. Os resultados inferem que as atividades desenvolvidas por empresas do setor elétrico causam significativos impactos sociais e ambientais, justificando dessa maneira a exigência de publicação do balanço social por parte da empresas desse setor.

Garcia et al. (2008), verificaram se as empresas que fazem parte do Índice de Sustentabilidade Empresarial tem objetivos de atender a sustentabilidade empresarial, e se na prática utilizam o referencial teórico da contabilidade ambiental. Concluindo que as empresas conhecem pouco sobre a contabilidade ambiental, o que existe é uma grande preocupação com a imagem das empresas frente ao mercado e a sociedade no sentido de reputação e marketing.

Rover et al. (2009), buscaram identificar os fatores determinantes da divulgação voluntária ambiental por empresas brasileiras potencialmente poluidoras. Analisaram os demonstrativos financeiros padronizados e os relatórios de sustentabilidade das empresas abertas com ações listadas na Bovespa no período de 2005 a 2007. Concluíram que nos três anos analisados, as empresas evidenciaram um total de 6.182 sentenças ambientais, sendo $73 \%$ divulgadas nos relatórios de sustentabilidade e $27 \%$ nas demonstrações financeiras padronizadas, e que as variáveis tamanho da empresa, sustentabilidade, empresa de auditoria e publicação do relatórios de sustentabilidade são relevantes a um nível de significância de 5\% 
para explicar o disclosure voluntário de informações ambientais.

As pesquisas realizadas com intuito de analisar as informações evidenciadas sobre o meio ambiente ganham espaço nas últimas décadas, demonstrando que as empresas vão gradativamente aumentando e melhorando as informações evidenciadas sobre a variável ambiental, diversas variáveis também influenciam na quantidade de informações evidenciadas e busca-se diferenciar as empresas que cumprem o papel ambiental e social, como por exemplo, listar estas empresas na composição de um índice.

\section{4 Índice de Sustentabilidade Empresarial (ISE)}

A nova abordagem exigida no mercado competitivo e globalizado para se fazer negócios, promove a responsabilidade social e reduz o uso de recursos naturais reduzindo consequentemente, os impactos negativos sobre o meio ambiente, preservando a integridade do planeta para as futuras gerações, sem deixar de lado a rentabilidade esperada pelo investidor (BOVESPA, 2009).

Vaz et al. (2008) mencionam que as empresas que buscam se manter no mercado e expandir seus empreendimentos, atraindo novos investidores, passaram a divulgar além das informações obrigatórias, informações adicionais a respeito da gestão empresarial e ações de responsabilidade social e ambiental.

A Bolsa de Valores de São Paulo (BOVESPA) junto com várias instituições regulamentadoras e orientadoras uniram esforços para criar um índice de ações para servir de referência aos investidores socialmente responsáveis, surgindo assim o Índice de Sustentabilidade Empresarial (ISE) (BOVESPA, 2009). O Índice de Sustentabilidade Empresarial foi criado em 2005, de acordo com Rezende e Santos (2006) a finalidade do ISE é possibilitar um ambiente de investimento e despertar a responsabilidade ética das corporações. Tem como conceito básico Triple Botton Line (TBL), juntamente com critérios de governança corporativa, seguindo as mesmas linhas do índice da Bolsa de Johannesburg (JSE) (REZENDE; SANTOS, 2006).

O Índice de Sustentabilidade Empresarial mede o retorno total de uma carteira teórica composta por ações de empresas com reconhecido comprometimento com a responsabilidade social e a sustentabilidade empresarial (BOVESPA, 2009).

A seleção das empresas que compõem o ISE é realizada por meio de questionários enviados as 150 organizações com ações mais líquidas, sendo avaliados e analisados por agências especializadas, que consolidam, organizam e conferem as informações prestadas pelas organizações (GONÇALVES; PIRANI; BORGER, 2007). Destas são escolhidas as melhores classificadas, podendo ser no máximo 40 entidades. A avaliação envolve elementos ambientais, sociais e 
econômico-financeiros, acrescidos mais três grupos de indicadores: a) critérios gerais; b) critérios de natureza do produto; e c) critérios de governança corporativa. Cabe ressaltar ainda que o preenchimento do questionário (com apenas perguntas objetivas) é voluntário, demonstrando o comprometimento da empresa com as questões de sustentabilidade, consideradas cada vez mais importantes em todo mundo (BOVESPA, 2009).

A Bovespa (2009) menciona que o peso das ações são ponderadas na carteira pelo valor de mercado das ações disponíveis à negociação. $\mathrm{O}$ índice tem como objetivo ser composto por empresas que se destacam em responsabilidade social, com sustentabilidade no longo prazo, ser um referencial do desempenho das ações desse tipo de empresa, ser percebido como tal pelo mercado (credibilidade), ser replicável, e estimular boas práticas por parte das demais.

\section{Métodos e Procedimentos da Pesquisa}

Nesta seção apresenta-se o delineamento da pesquisa, a caracterização da amostra e a forma de coleta e análise dos dados.

\subsection{Delineamento da Pesquisa}

O presente estudo utiliza uma abordagem descritiva. Segundo Triviños (1987), o estudo descritivo requer delimitações de técnicas, métodos, modelos e teorias. Para Raupp e Beuren (2008, p. 81): "a pesquisa descritiva configura-se como um estudo intermediário entre a pesquisa exploratória e a explicativa, ou seja, não é tão preliminar como a primeira e não tão aprofundada como a segunda".

A pesquisa quanto aos procedimentos, caracteriza-se como pesquisa documental. Para Beuren (2008), as pesquisas documentais utilizam materiais que não recebem análise, mas que podem ser reelaborados de acordo com os objetos da pesquisa. Martins e Theóphilo (2007 p. 85) explicam que a pesquisa documental "não levanta material editado - livros, periódicos etc-, mas busca material que não foi editado, como cartas, memorandos, correspondências de outros tipos, avisos, agendas, propostas, relatórios, estudos, avaliações etc." O estudo é documental porque utilizou relatórios da administração (RA) e notas explicativas (NE) como fontes de dados para análise.

Quanto à abordagem do problema, classifica-se como qualitativa. Richardson $(1989$, p. 38) destaca que a abordagem qualitativa "difere, em princípio, do quantitativo à medida que não emprega um instrumental estatístico como base do processo de análise". É qualitativa porque procurou verificar as informações relacionadas aos custos ambientais evidenciadas nos relatórios de administração e notas explicativas das empresas que compõe o Índice de Sustentabilidade Em- 
presarial.

\subsection{Amostra da Pesquisa}

A amostra da pesquisa constitui-se de todas as empresas que compõem o Índice de Sustentabilidade Empresarial 2009/2010 da Bovespa. O ISE é formado por companhias de 13 diferentes segmentos da Bovespa e de três níveis de governança corporativa, que correspondem a 24 empresas, as demais classificam-se no nível tradicional da Bovespa, totalizando 29 empresas.

\subsection{Coleta e Análise dos Dados}

A busca dos dados ocorreu em 58 relatórios, sendo relatórios de administração e notas explicativas do ano de 2008 disponíveis no sitio da Bovespa. Verificou-se a evidenciação das informações nas empresas que compõem o Índice de Sustentabilidade Empresarial, por meio do modelo de Rover, Borba e Borgert (2008), permitindo realizar análise de conteúdo nos relatórios de administração e notas explicativas. Inicialmente quantificam-se os trechos dos RA e NE para identificar as palavras: custo, meio ambiente, ambiental, sustentabilidade e ecologia. No Quadro 1 apresenta-se o constructo das estratégias de análise da evidenciação ambiental.

\section{Quadro 1: Estratégias de análise da evidenciação ambiental}

\begin{tabular}{|c|}
\hline Categoria 1: Custos ambientais para controlar ocorrência de impactos ambientais \\
\hline 1.1 - Custos de prevenção de poluição (ar, água e solo) \\
\hline 1.2 - Custos de conservação global ambiental \\
\hline 1.3 - Custos para gestão de resíduos \\
\hline Categoria 2: Custos de conservação em atividades de pesquisa e desenvolvimento \\
\hline Categoria 3: Custos ambientais em atividades sociais \\
\hline Custos com pesquisa e desenvolvimento ou custos para planejar impactos ambientais de produtos \\
\hline 3.1 - Custos para proteção da natureza, reflorestamento, embelezamento e melhorias para o meio ambiente \\
\hline 3.2 - Custos para distribuição de informações ambientais \\
\hline 3.3 - Custos para contribuição e apoio de grupos ambientais \\
\hline Categoria 4: Custos Correspondentes a danos ambientais \\
\hline 4.1 - Custos com recuperação de contaminação ambiental \\
\hline 4.2 - Custos com indenizações e penalidades ambientais \\
\hline
\end{tabular}

Fonte: Adaptado de Rover, Borba e Borgert (2008).

No Quadro 1, apresenta-se o modelo utilizado para analisar os custos ambientais evidenciados nos relatório de administração e notas explicativas integrantes das demonstrações financeiras padronizadas das empresas utilizadas no estudo, que é apresentado em quatro categorias relacionadas aos custos ambientais. 
Na sequência foi feita a interpretação do trecho onde a palavra estava inserida, com intuito de identificar este trecho ao contexto da pesquisa, aplicou-se a técnica de análise de conteúdo nos relatórios. Bardin (1977) cita que a técnica de análise de conteúdo prevê estudo de interpretação de textos para compreender a construção de resultados. A autora menciona ainda que não se trata de um instrumento, mas de um apanhado de apetrechos, com maior rigor, será um único instrumento, mas marcado por uma grande disparidade de formas e adaptável a um campo de aplicação muito vasto que são as comunicações.

Após a análise de conteúdo dos RA e NE, os dados coletados foram organizados em quadros, para análise da evidenciação das informações dos custos ambientais. Além disso, alguns relatos mais específicos foram extraídos desses documentos pesquisados para elucidar a evidenciação das informações dos custos ambientais nas organizações que compõem o ISE.

\section{Análise dos Dados}

Nesta seção, apresenta-se: (i) a caracterização das empresas que compõem a amostra; e (ii) a evidenciação das informações nas empresas que compõem o ISE, de acordo com a categorização proposta por Rover, Borba e Borgert (2008). Os tópicos desenvolvidos posteriormente têm a finalidade de cumprir os objetivos propostos por esta pesquisa.

\subsection{Caracterização das Empresas que Compõem a Amostra}

As empresas analisadas neste estudo compõem o índice de sustentabilidade empresarial 2009/2010 da Bovespa. A amostra compreende companhias de 13 diferentes segmentos da Bovespa e de três níveis de governança corporativa, que correspondem a 24 empresas. As demais classificam-se no nível tradicional da Bovespa.

A caracterização das empresas demonstra como os diferentes segmentos da Bovespa estão representados no ISE e quais níveis de negociação diferenciada predominam entre as empresas do ISE. A Figura 1 apresenta os segmentos e os níveis da Bovespa caracterizando a amostra do estudo. 
Figura 1: Caracterização das empresas que compõem o ISE
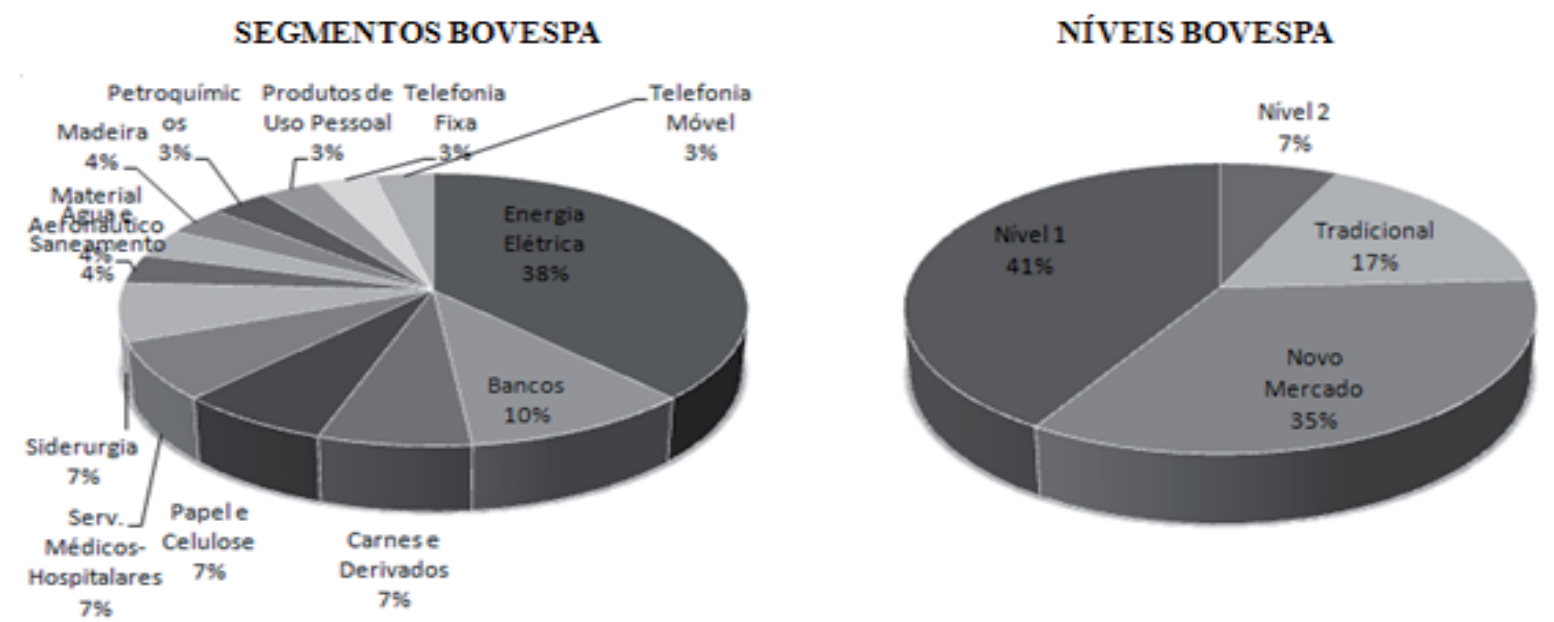

Fonte: Dados da pesqusia.

$\mathrm{Na}$ caracterização das empresas que compõem o ISE, verifica-se que a maioria das empresas investigadas pertencem ao setor de Energia Elétrica, sendo $38 \%$ das empresas do ISE. Na sequência o setor Bancário apresenta 10\%, ocupando o segundo lugar dentre as empresas que compõem a amostra, com representação semelhante, tem-se o segmento de Carnes e Derivados, Papel e Celulose, Serviços Médicos e Hospitalares e Siderurgia todos com 7\%. Fechando a restrita segmentação das empresas que compõem o ISE encontram-se os segmentos de atuação Material Aeronáutico, Água e Saneamento, Madeira, Petroquímico, Produtos de Uso Pessoal, Telefonia Fixa e Telefonia Móvel. Portanto fica evidente o predomínio de empresas do segmento de Energia Elétrica dentre as empresas que compõem o ISE, o que pode ser explicado pelo alto grau de exigências impostas pelos órgãos reguladores do setor, principalmente tratando-se de ações ambientais, corroborando com o estudo realizado por Azevedo e Cruz (2007).

Evidencia-se que $83 \%$ das empresas que compõem o ISE fazem parte dos níveis de governança corporativa da Bovespa, destes predominam empresas listados no Nível 1 de governança corporativa, sendo 41\%, as companhias que fazem parte do novo mercado representam 35\%, e 7\% estão listadas no Nível 2. Percebe-se que as exigências necessárias para fazer parte dos níveis de governança corporativa, alinham-se a algumas exigências para compor o ISE.

\subsection{Evidenciação dos Custos Ambientais para Controlar Ocorrência de Impactos Ambientais}

A análise dos custos ambientais evidenciados pelas empresas que compõem o Índice de Sustentabilidade Empresarial, procedeu-se por meio do modelo desenvolvido por Rover, Borba e Borgert (2008). Analisando-se as informações sobre 
custos ambientais mencionadas pelas organizações objeto do estudo, verifica-se as 4 categorias propostas, iniciando pela Categoria 1 - Custos ambientais para controlar ocorrência de impactos ambientais, conforme o Quadro 2 que apresenta a quantidade de organizações que evidenciaram os itens referentes a categoria e participação destas na amostra total.

Quadro 2: Custos dos impactos ambientais evidenciadas pelas empresas do ISE

\begin{tabular}{|l|r|r|r|r|r|r|}
\hline \multirow{2}{*}{$\begin{array}{c}\text { Categoria 1: Custos a mbientais para controlar ocorrência de } \\
\text { impactos ambientais }\end{array}$} & \multicolumn{2}{|c|}{$\begin{array}{c}\text { No. de empresas } \\
\text { que evidenciam }\end{array}$} & \multicolumn{2}{|c|}{$\begin{array}{c}\text { \% de empresas } \\
\text { que evidencia m/ } \\
\text { Amostra Total }\end{array}$} \\
\cline { 2 - 7 } & RA & NE & Total & RA & NE & Total \\
\hline 1.1 - Custos de prevenção de poluição (ar, água e solo) & 4 & 3 & 7 & $14 \%$ & $10 \%$ & $12 \%$ \\
\hline 1.2 - Custos de conservação global ambiental & 11 & 3 & 14 & $38 \%$ & $10 \%$ & $24 \%$ \\
\hline 1.3 - Custos para gestão de resíduos & 4 & 0 & 4 & $14 \%$ & $0 \%$ & $7 \%$ \\
\hline
\end{tabular}

Fonte: Dados da pesqusia.

Observa-se que a Categoria 1, custos ambientais para controlar a ocorrência de impactos ambientais, evidencia as três subcategorias analisadas, predominam as evidenciações por parte das empresas nos relatórios de administração, em que o item 1.2 - Custos de conservação global ambiental possui maior evidenciação. Em segundo lugar está a subcategoria 1.1 - Custos de prevenção de poluição do ar, solo e água com 7 empresas neste item. Apenas em 4 empresas foi possível verificar a evidenciação dos custos para gestão de resíduos ambientais, ficando assim como o item menos evidenciado na análise.

A subcategoria custos de conservação global ambiental aparece mais comumente nas empresas analisadas, representando $38 \%$ das empresas analisadas, portanto quando verifica-se as informações evidenciadas pelas empresas do ISE referentes a custos ambientais para controlar ocorrência de impactos ambientais, constata-se que as empresas estão mais preocupadas em evidenciar informações dos custos referentes a conservação global ambiental, e não tratando mais de evidenciar os gastos com itens específicos.

Quanto às informações divulgadas no enfoque da Categoria 1 - Custos ambientais para controlar a ocorrência de impactos ambientais destaca-se a seguinte evidenciação:

Do total de gastos com meio ambiente no exercício de 2008, R\$ 5 milhões foram imputado são resultado do exercício e R\$ 7 milhões foram destinados à investimentos ao ativo imobilizado. A política de capitalização dos gastos é efetuada com base nas instruções gerais do MCSPEE. (Notas explicativas 2008, AES Tiete). [grifo nosso] 
Verifica-se que as companhias vêm evidenciando informações globais sobre os custos ambientais, conforme visto na Categoria 1, na evidenciação da AES Tiete. Verifica-se que a mesma enquadra-se na subcategoria 2 - Custos de conservação global ambiental, que apresentou mais evidenciações das empresas do ISE. Verifica-se que muitas das empresas do ISE optam por divulgar os custos de conservação global ambiental.

Observa-se que comparativamente ao estudo de Rover, Borba e Borgert (2008) houve uma melhora na evidenciação dos custos ambientais para controlar ocorrência de impactos ambientais. Nesta categoria, Rover, Borba e Borgert (2008) encontraram 10 evidenciações, enquanto a presente pesquisa identificou 25 , como observado no Quadro 2. É observada a convergência no que se refere a subcategoria custos para gestão de resíduos, no qual ambas as pesquisas apontam o menor número de evidenciação. Nos custos de conservação global ambiental também apresentou convergência como a subcategoria que mais observações foram identificadas nas pesquisas.

6.3 Evidenciação dos Custos de Conservação em Atividades de Pesquisa e Desenvolvimento

Para a análise da evidenciação dos custos de conservação em atividades de pesquisa e desenvolvimento também utilizou-se o modelo desenvolvido por Rover, Borba e Borgert (2008). O resultado quanto a Categoria 2 é demonstrada no Quadro 3.

Quadro 3: Custos de conservação em P\&D evidenciadas pelas empresas do ISE

\begin{tabular}{|l|r|r|r|r|r|r|}
\hline \multirow{2}{*}{$\begin{array}{c}\text { Categoria 2: Custos de conservação em atividades de pesquisa } \\
\text { e desenvolvimento }\end{array}$} & \multicolumn{2}{|c|}{$\begin{array}{c}\text { No. de empresas } \\
\text { que evidenciam }\end{array}$} & \multicolumn{3}{|c|}{$\begin{array}{c}\text { \% de empresas } \\
\text { que evidenciam/ } \\
\text { Amostra Total }\end{array}$} \\
\cline { 2 - 8 } & RA & NE & Total & RA & NE & Total \\
\hline $\begin{array}{l}2.1 \text { - Custos com pesquisa e desenvolvimento ou custos para } \\
\text { planejar impactos ambientais de produtos }\end{array}$ & 2 & 3 & 5 & $7 \%$ & $10 \%$ & $9 \%$ \\
\hline
\end{tabular}

Fonte: Dados da pesqusia.

No Quadro 3 foi possível verificar que as empresas evidenciam informações de custos com pesquisa e desenvolvimento ou custos para planejar impactos ambientais de produtos, tanto nos relatórios de administração quanto nas notas explicativas.

Foram encontradas informações em 5 relatórios analisados, nos 58 verificados. Estas evidenciações correspondem a apenas 9\% do total de empresas analisadas, demonstrando um baixo nível de evidenciação nas empresas do ISE, neste item. Entretanto, ainda apresenta melhora em relação a pesquisa de Rover, 
Borba e Borgert (2008) que obtiveram somente 1 sentença.

Para ilustrar as informações divulgadas a respeito da Categoria 2 - Custos de conservação em atividades de pesquisa e desenvolvimento, resgata-se a evidenciação da Tractebel nas notas explicativas de 2008.

Como forma de buscar soluções sustentáveis para suas operações e interagir com as instituições e fundações de ensino e pesquisa locais, a Tractebel desenvolve seu programa anual de pesquisa e desenvolvimento, conforme determinação da Aneel, no qual em 2008 foram investidos $\underline{R} \$ 20,0$ milhões em diversos projetos, nas seguintes áreas de criação e investimento: eficiência energética; fonte renovável ou alternativa de geração de energia elétrica; meio ambiente; qualidade e confiabilidade; planejamento e operação de sistemas elétricos; supervisão, controle e proteção de sistemas elétricos; medição e faturamento; e novos materiais e componentes. (Relatório da Administração 2008, Tractebel). [grifo nosso]

Ações com objetivos de conservação em atividades de pesquisa e desenvolvimento são realizadas nas empresas analisadas, podendo destacar que a sociedade exige cada vez mais responsabilidade das empresas. Entende-se que estas empresas necessitam buscar soluções e incluir em seus planejamentos e orçamentos montantes necessários para estas realizações, como os evidenciados pela Tractebel, em seu relatório de administração.

\subsection{Evidenciação dos Custos Ambientais em Atividades Sociais}

Outra categoria analisada foram os custos ambientais em atividades sociais, nas quais apresentam-se no Quadro 4, segregadas em relação aos RA e as NE.

Quadro 4: Custos ambientais em atividades sociais evidenciadas pelas empresas do ISE

\begin{tabular}{|l|r|r|r|r|r|r|}
\hline \multirow{2}{*}{ Categoria 3: Custos ambientais em atividades sociais } & \multicolumn{3}{|c|}{$\begin{array}{c}\text { No. de empresas } \\
\text { que evidenciam }\end{array}$} & \multicolumn{3}{c|}{$\begin{array}{c}\% \text { de empresas } \\
\text { que evidenciam/ } \\
\text { Amostra Total }\end{array}$} \\
\cline { 2 - 8 } & RA & NE & Total & RA & NE & Total \\
\hline $\begin{array}{l}\text { 3.1 - Custos para proteção da natureza, reflorestamento, } \\
\text { embelezamento e melhorias para o meio ambiente }\end{array}$ & 4 & 1 & 5 & $14 \%$ & $3 \%$ & $9 \%$ \\
\hline 3.2 - Custos para distribuição de informações ambientais & 0 & 1 & 1 & $0 \%$ & $3 \%$ & $2 \%$ \\
\hline 3.3 - Custos para contribuição e apoio de grupos ambientais & 3 & 0 & 3 & $10 \%$ & $0 \%$ & $5 \%$ \\
\hline
\end{tabular}

Fonte: Dados da pesqusia.

$\mathrm{Na}$ categoria 3, custos ambientais em atividades sociais, percebe-se que a quantidade de empresas que evidenciam informações desta natureza é pouco 
significativa, e que são mais evidenciadas nos relatórios de administração. Dentre as categorias analisadas a subcategoria 3.1 - Custos para proteção da natureza, reflorestamento, embelezamento e melhorias para o meio ambiente apresentou maior evidenciação nas empresas do Índice de Sustentabilidade Empresarial, o que converge com o estudo de Rover, Borba e Borgert (2008) como a subcategoria que mais teve sentenças apresentadas. Por outro lado, os custos para distribuição de informações ambientais que corresponde a subcategoria 3.2, apresentou menor evidenciação nas empresas analisadas, correspondendo a apenas uma empresa. Nesta subcategoria, o estudo de Rover, Borba e Borgert (2008) também apresentou menor evidenciação, juntamente com a subcategoria custos para contribuição e apoio de grupos ambientais. $O$ fato de ser uma categoria que está vinculada a atividades sociais, em parte relacionados a terceiros, pode ser um fator que explique a baixa evidenciação pelo fato de existir baixo comprometimento das empresas por atividades sociais. Isso pode ocorrer devido a esta categoria não sofrer diretamente com questões compulsórias, o que faz que outras categorias sobressaiam sobre esta. Entretanto, cabe destacar que a análise ocorreu com empresas que compõe o ISE, o que se esperava ações diferenciadas dessas empresas que refletissem na evidenciação de custos ambientais em atividades sociais.

A representatividade das empresas que evidenciaram informações nessa categoria não ultrapassou $10 \%$ em cada subcategoria analisada, reforçando a baixa evidenciação encontrada neste item por parte das empresas que fazem parte do Índice de Sustentabilidade Empresarial.

Destaca-se na Categoria 3 a evidenciação da Perdigão em suas notas explicativas do ano de 2008 em que a evidenciação ilustra os custos ambientais em atividades sociais.

Investimentos em prevenção de danos ao meio ambiente: os gastos relacionados ao atendimento de regulamentos ambientais são considerados como custo de produção ou capitalizados quando incorridos. Na avaliação da Administração, a provisão para perdas relativas a questões ambientais constituída atualmente é suficiente para cobrir estes gastos. (Notas explicativas 2008, Perdigão). [grifo nosso]

A Perdigão investe em prevenções de danos ambientais para atender aos regulamentos ambientais é evidenciada assim a subcategoria 3.2 referente aos custos para distribuição de informações ambientais, sendo esta a única evidenciação encontrada neste subitem. Demonstrando a baixa representatividade nas evidenciações das empresas do ISE nas informações de custos ambientais em atividades sociais. 
6.5 Evidenciação dos Custos Correspondentes a Danos Ambientais

Os custos correspondentes a danos ambientais evidenciados pelas empresas que compõem o Índice de Sustentabilidade Empresarial foram verificados por meio das informações constantes nos relatórios de administração e notas explicativas observando-se a categorização proposta. No Quadro 5 apresentam-se as evidenciações das empresas do ISE, quanto o item custos correspondentes a danos ambientais, quantidade e percentual de empresas considerando a amostra total.

Quadro 5: Custos de danos ambientais evidenciadas pelas empresas do ISE

\begin{tabular}{|l|r|r|r|r|r|r|r|}
\hline \multirow{2}{*}{ Categoria 4: Custos correspondentes a danos ambientais } & \multicolumn{2}{|c|}{$\begin{array}{c}\text { No. de empresas } \\
\text { que evidenciam }\end{array}$} & \multicolumn{3}{c|}{$\begin{array}{c}\text { \% de empresas } \\
\text { que evidenciam/ } \\
\text { Amostra Total }\end{array}$} \\
\cline { 2 - 7 } & RA & NE & Total & RA & NE & Total \\
\hline 4.1 - Custos com recuperação de contaminação ambiental & 1 & 2 & 3 & $3 \%$ & $7 \%$ & $5 \%$ \\
\hline 4.2 - Custos com indenizações e penalidades ambientais & 2 & 5 & 7 & $7 \%$ & $17 \%$ & $12 \%$ \\
\hline
\end{tabular}

Fonte: Dados da pesqusia.

O Quadro 5 apresenta informações dos custos correspondentes a danos ambientais, neste item as evidenciações foram mais encontradas nas notas explicativas do que nos relatórios de administração. Verifica-se que a Categoria 4 apresenta a evidenciação por parte de 5 empresas referentes a subcategoria 4.2 - Custos com indenizações e penalidades ambientais nas notas explicativas.

A subcategoria 4.2 - Custos com indenizações e penalidades ambientais representa $12 \%$ do total de empresas do Índice de Sustentabilidade Empresarial da Bovespa e os custos com recuperação de contaminação ambiental representam apenas $5 \%$ das empresas da análise. Destaca-se que a participação deste item no total das empresas que compõem o ISE é pouco representativa.

Esta foi a única categoria que apresentou resultado divergente ao estudo de Rover, Borba e Borgert (2008). Em quanto nesta pesquisa, os custos com recuperação de contaminação ambiental e os custos com indenizações e penalidades ambientais representam 3 e 7 sentenças respectivamente, na pesquisa de Rover, Borba e Borgert (2008) são 9 e 4 sentenças.

$\mathrm{Na}$ Categoria 3, correspondente aos custos correspondentes a danos ambientais, foi extraída parte da informação evidenciada nas notas explicativas da empresa Sabesp.

Pagamento de indenização por danos ao meio ambiente causados ao solo, a fontes de água e a corpos d'água subterrâneos e superficiais que não podem ser recuperados. O Tribunal de Justiça decidiu a favor 
dos itens (i), (iii) e (iv) acima. O perito técnico do tribunal calculou a indenização por danos ambientais no valor de R\$826.800,00 (oitocentos e vinte e seis mil e oitocentos reais), ou alternativamente, em R \$ 5,8 milhões, em 17 de outubro de 2006. Este montante ainda está sob discussão e sujeita a uma decisão final pelo Tribunal. (Notas explicativas 2008, Sabesp). [grifo nosso]

As empresas evidenciaram mais informações referentes a subcategoria de custos com indenizações e penalidades ambientais, ou seja, custos decorrentes de possíveis irregularidades, reafirmadas com valores a desembolsar por parte das empresas. A Sabesp foi obrigada a pagar alguns valores relativos a danos ambientais, causados em áreas que não podem mais ser recuperadas, uma forma de punir as organizações pelos descasos com o meio ambiente. Com a constatação de que a categoria de custos correspondentes a danos ambientais representa o segundo maior número de sentenças encontradas, verifica-se que este resultado converge com o entendimento de que as empresas acabam evidenciando aspectos ambientais por questões compulsórias, como os custos de recuperação por contaminação ambiental e com indenizações e penalidades ambientais.

\subsection{Sintese das Categorias Analisadas}

Nas informações das empresas que compõem o Índice de Sustentabilidade Empresarial evidenciou-se quatro categorias de acordo com o modelo proposto por Rover, Borba e Borgert (2008). Assim tem-se a análise destas categorias investigadas nos relatórios das organizações que fazem parte deste estudo. O Quadro 6 possibilita comparar as categorias verificadas na pesquisa.

Quadro 6: Categorias de custos ambientais evidenciadas pelas empresas do ISE

\begin{tabular}{|c|c|c|c|c|c|}
\hline \multirow{2}{*}{ Categorias analisadas } & \multicolumn{3}{|c|}{ Itens evidenciados } & \multicolumn{2}{|c|}{ Total de empresas } \\
\hline & RA & $\mathbf{N E}$ & Total & Quant. & $\%$ \\
\hline $\begin{array}{l}\text { Categoria 1: Custos ambientais para controlar ocorrência de } \\
\text { impactos ambientais }\end{array}$ & 19 & 6 & 25 & 13 & $45 \%$ \\
\hline $\begin{array}{l}\text { Categoria 2: Custos de conservação em atividades de } \\
\text { pesquisa e desenvolvimento }\end{array}$ & 2 & 3 & 5 & 4 & $14 \%$ \\
\hline Categoria 3: Custos ambientais em atividades sociais & 7 & 2 & 9 & 7 & $24 \%$ \\
\hline Categoria 4: Custos correspondentes a danos ambientais & 3 & 7 & 10 & 8 & $28 \%$ \\
\hline Total & 31 & 18 & 49 & - & \\
\hline
\end{tabular}

Fonte: Dados da Pesquisa

Verifica-se que a Categoria 1 - Custos ambientais para controlar ocorrência de impactos ambientais é a categoria mais evidenciada pelas empresas que compõem o Índice de Sustentabilidade Empresarial, predominando o item custos 
de preservação global, a categoria corresponde a 45\% das empresas analisadas no estudo que evidenciaram alguns itens requeridos. Esta categoria apresentou melhoria ao estudo de Rover, Borba e Borgert (2008) quando encontraram 9 sentenças na categoria. Na sequência encontram-se as categorias: 4 - Custos correspondentes a danos ambientais e 3 - Custos ambientais em atividades sociais, com respectivamente $28 \%$ e $24 \%$ das empresas que evidenciaram algum dos itens analisados. Com evidenciação menos expressiva encontra-se Custos de conservação em atividades de pesquisa e desenvolvimento, com 14\% das empresas que compõem o ISE, o que corresponde a 4 empresas apenas.

Denota-se ainda que ao observar 4 categorias e 9 subcategorias em 29 relatórios de administração e 29 notas explicativas, a possibilidade máxima seria de 522 observações. A pesquisa identifica 49 observações, que correspondem a 9\% do total possível de evidenciação dos custos nas empresas que compõem o Índice de Sustentabilidade Empresarial, com base no modelo proposto por Rover, Borba e Borgert (2008). A baixa evidenciação dos custos ambientais corrobora com os resultados do estudo de Leite, Ribeiro e Pacheco (2007) onde observaram que a evidenciação referente a passivos ambientais e interações com o meio ambiente nos relatórios de administração e notas explicativas vêm sendo apresentado com poucos detalhes e pequeno grau de evidenciação.

\subsection{Empresas do ISE que Evidenciaram Custos Ambientais}

No Quadro 7 apresenta-se as empresas que compõem o Índice de Sustentabilidade Empresarial, com as organizações que evidenciaram no mínimo uma das subcategorias analisadas nos relatórios de administração e notas explicativas, quanto aos custos ambientais.

Observa-se no Quadro 7 demonstra que 16 empresas das 29 que compõem o Índice de Sustentabilidade Empresarial evidenciam no relatório de administração ou nas notas explicativas alguma das categorias analisadas, o que corresponde a mais de 50\% das empresas do ISE. No estudo de Rover, Borba e Borgert (2008), 13 empresas evidenciaram informações referentes a custos ambientais, portanto também convergem aos resultados de Campbell (2004) onde verificou um aumento na divulgação de informações ambientais das empresas analisadas, visto que no estudo de Rover, Borba e Borgert (2008) foram analisadas as empresas do ISE 2006/2007 e relatórios de 2006. No presente estudo verificou-se as empresas do ISE 2009/2010 e relatórios de 2008, passando de 13 para 16 empresas, que corresponde a $23 \%$ a mais de empresas que compõem o ISE que evidenciaram informações sobre custos ambientais. 
Quadro 7: Empresas do ISE que evidenciaram custos ambientais

\begin{tabular}{|c|c|c|c|c|c|}
\hline EMPRESA & SEGMENTO & $\begin{array}{c}\text { CUSTOS } \\
\text { AMBIENTAIS }\end{array}$ & EMPRESA & SEGMENTO & $\begin{array}{c}\text { CUSTOS } \\
\text { AMBIENTAIS }\end{array}$ \\
\hline CEMIG & Energia Elétrica & SIM & PERDIGAO S/A & Carnes e Derivados & SIM \\
\hline CESP & Energia Elétrica & SIM & $\begin{array}{l}\text { SUZANO } \\
\text { PAPEL }\end{array}$ & Papel e Celulose & SIM \\
\hline ELETROBRAS & Energia Elétrica & SIM & V C P & Papel e Celulose & \\
\hline CELESC & Energia Elétrica & & DASA & Serv. Méd-Hosp. & \\
\hline ELETROPAULO & Energia Elétrica & SIM & ODONTOPREV & Serv. Méd-Hosp. & \\
\hline CPFL ENERGIA & Energia Elétrica & & GERDAU & Siderurgia & \\
\hline TRACTEBEL & Energia Elétrica & SIM & GERDAU MET & Siderurgia & \\
\hline AES TIETE & Energia Elétrica & SIM & EMBRAER & Mat. Aeronáutico & SIM \\
\hline COELCE & Energia Elétrica & SIM & SABESP & Água e Saneamento & SIM \\
\hline LIGHT S/A & Energia Elétrica & SIM & DURATEX & Madeira & SIM \\
\hline ENERGIAS BR & Energia Elétrica & & BRASKEM & Petroquímicos & SIM \\
\hline BRADESCO & Bancos & & NATURA & Uso Pessoal & SIM \\
\hline ITAUUNIBANCO & Bancos & & TELEMAR & Telefonia Fixa & SIM \\
\hline BCO BRASIL & Bancos & & TIM PART S/A & Telefonia Móvel & \\
\hline SADIA S/A & $\begin{array}{c}\text { Carnes e } \\
\text { Derivados }\end{array}$ & & & & \\
\hline
\end{tabular}

Fonte: Dados da pesqusia.

Verifica-se que entre os setores analisados o segmento Energia Elétrica possui a maioria das empresas com algum tipo de evidenciação. Os demais setores que evidenciam custos ambientais possuem apenas uma empresa com evidenciação. O segmento Bancos apresenta 3 empresas na participação do ISE, representando $10 \%$ das empresas, porém estas organizações não evidenciaram nenhuma das categorias do modelo proposto.

Assim como os resultados encontrados por Gadenne e Zaman (2001) verifica-se que muitas companhias não evidenciam o enfoque de custos ambientais, principalmente pelo fato da divulgação ser predominantemente voluntária, corroborando com Raiborn, Butler e Massoud (2011) ao constatar que o sistema de informações contábeis tem falhado em evidenciar os custos ambientais.

\section{Considerações Finais}

O objetivo da pesquisa foi identificar as informações relacionadas aos custos ambientais mais evidenciadas nos relatórios de administração e notas explicativas das empresas que compõe o Índice de Sustentabilidade Empresarial. Para tal foi utilizado um modelo elaborado por Rover, Borba e Borgert (2008), possibilitando identificar as informações evidenciadas sobre custos ambientais nos relatórios de administração e notas explicativas do ano de 2008.

A pesquisa propôs ainda a caracterização das empresas que compõem o Índice de Sustentabilidade Empresarial de acordo com o segmento de listagem e quais níveis de negociação diferenciada predominam entre as organizações analisadas. Na composição do Índice de Sustentabilidade Empresarial da Bovespa 
predominam companhias do segmento de Energia Elétrica com participação de $38 \%$ das empresas do ISE. Verifica-se também que prevalecem as empresas listadas nos níveis de governança corporativa da Bovespa, participando com 83\% das empresas listadas.

Pode-se inferir que as exigências da governança corporativa e o alto grau de exigências impostas pelos órgãos reguladores do setor de Energia Elétrica, principalmente tratando-se de ações ambientais, influenciam no domínio de empresas com estas características na composição do ISE, visto que o índice é composto por ações de empresas com reconhecido comprometimento com a responsabilidade social e a sustentabilidade empresarial.

Quanto às informações mais evidenciadas nas companhias que compõem o Índice de Sustentabilidade Empresarial, verificou-se que a Categoria 1 - Custos ambientais para controlar ocorrência de impactos ambientais, é a mais evidenciada. A categoria corresponde a 45\% das empresas analisadas no estudo que evidenciaram alguns itens requeridos, predominando o item custos de preservação global. Mais de 50\% das empresas do ISE evidenciam no relatório de administração ou nas notas explicativas alguma das categorias analisadas, predominando entre os setores analisados o segmento Energia Elétrica, o qual possui a maioria das empresas com algum tipo de evidenciação.

Com base nas observações realizadas por meio de análise de conteúdo nas companhias que compõem o ISE, verificou-se que a possibilidade máxima de evidenciação dos custos ambientais seria de 522 observações impostas pelo modelo utilizado e pelos relatórios analisados. Este estudo identificou 49 observações que correspondem a 9\% do total possível de evidenciação dos custos ambientais nas empresas que compõem o ISE, com base no modelo proposto por Rover, Borba e Borgert (2008).

Conclui-se que as informações dos custos ambientais mais evidenciadas pelas empresas que compõem o ISE, referem-se aos "custos para controlar impactos ambientais". Pelas observações realizadas pode-se inferir que os achados evidenciados nesta pesquisa, denotam pouca evidenciação dos itens analisados por meio do modelo utilizado, tendo pouca representatividade quando comparado às possibilidades apresentadas pelo modelo. Neste sentido, por serem empresas que fazem parte de um índice que considera questões ambientais na escolha das empresas participantes, compreende-se que a evidenciação de informações de custos ambientais deva ser mais comumente explicitada nestes relatórios, que servem como fontes informacionais para tomada de decisão dos diversos usuários. É significante, ainda mencionar que mesmo com o baixo nível de evidenciação com base no modelo aplicado, o número de empresas que compõem o ISE e evidenciam informações sobre custos ambientais aumentou.

Devido às limitações do estudo, recomenda-se a realização de uma pes- 
quisa englobando empresas que não fazem parte do Índice de Sustentabilidade Empresarial da Bovespa, a fim de verificar diferenças de evidenciação de informações sobre custos ambientais, contribuindo com este e com os demais estudos sobre o tema.

\section{Referencias}

AZEVEDO, Tânia C.; CRUZ, Cláudia F. Evidenciação das informações de natureza sócio-ambiental divulgadas pelas distribuidoras de energia elétrica que atuam na região nordeste do Brasil e sua relação com indicadores de desempenho empresarial. In: Congresso Brasileiro de Custos, 14., 2007. João Pessoa-PB. Anais... João Pessoa-PB: CBC, 2007.CD-ROM.

BARDIN, Laurence. Análise de conteúdo. Lisboa: Edições 70, 1977. 225p.

BEN, Fernando ; SCHNEIDER, Vania E. Evidenciação dos Custos Ambientais e da Contabilidade Ambiental em Empresa Brasileiras. In: 1 er Congrès Transatlantique de Comptabilité, Audit, Contrôle de Gestion, Gestion de Côuts et Mondialisation y X Congresso del Instituto Internacional de Costos, 2007, Lyon - França. CDROM. Anais... 2007. v. 1. p. 225-240. CD-ROM.

BERGAMINI JUNIOR, Sebastião. Custos emergentes na contabilidade ambiental. Pensar Contábil, Rio de Janeiro, n.9, p.3-11, ago-out. 2000.

BEUREN et al. (Org.). Como Elaborar Trabalhos Monográficos em Contabilidade. 3 ed., São Paulo: Atlas, 2008.

BOLSA DE VALORES DE SÃO PAULO (BOVESPA). Disponível em: <www. bovespa.com.br>. Acesso em: 04 de setembro de 2009.

BORBA, J. A.; NAZÁRIO, L.. Contabilidade ambiental: A preocupação empresarial com o meio ambiente através da evidenciação da terminologia comumente empregada nas demonstrações contábeis publicadas no Brasil. In: ENANPAD, XXVII, 2003, Atibaia. Anais... Atibaia: Anpad, 2003. CD-ROM.

BURNETT, Royce D.; HANSEN, Don R. Ecoefficiency: defining a role for environmental cost management. Accounting, Organizations and Society. n. 33, p. 551-581, 2008.

CALIXTO, Laura. Uma análise da evidenciação ambiental de companhias brasileiras - de 1997 a 2005. In: Congresso Brasileiro de Custos, 13., 2006. Belo Horizonte. Anais... Belo Horizonte: CBC, 2006. CD-ROM.

CAMPBELL, David. A longitudinal and cross-sectional analysis of environmental 
disclosure in UK companies - a research note. The British Accounting Review, n.36, p.107-117, 2004.

GARCIA, Regis et al. Contabilidade ambiental e sustentabilidade empresarial: estudo das empresas do ISE - BOVESPA. Congresso Brasileiro de Custos. 15., 2008. Curitiba. Anais...Curitiba: CBC, 2008.CD-ROM.

GADENNE, David; ZAMAN, Monir. Australian environmental management accounting: an exploratory study of current corporate practice and strategic intent. 2001. Disponível em <www.conferences.unimelb.edu.au/> Acesso em 02/08/2009.

GONÇALVES, R. C. M. G.; PIRANI, D. C.; BORGER, F. G. Qualidade das Informações sobre Responsabilidade Social Divulgadas pelos Bancos Privados com Ações Listadas no Índice de Sustentabilidade Empresarial da Bovespa. In: Encontro Nacional da Associação de Pós-Graduação e Pesquisa em Administração, 31, 2007, Rio de Janeiro. Anais... Salvador: ANPAD, 2007. CD-ROM.

LU, Cherie. The implications of environmental costs on air passenger demand for different airline business models. Journal of Air Transport Management. v. 15 , p. 158-165, 2009.

MARTINS, Eliseu et al. Normas e práticas contábeis no Brasil. 2. ed. São Paulo: Atlas, 1994. 676p.

MARTINS, Gilberto de Andrade; THEÓPHILO, Carlos Renato. Metodologia da investigação científica para ciências sociais aplicadas. São Paulo: Atlas, 2007.

RAIBORN, Cecily A.; BUTLER, Janet B.; MASSOUD, Marc F. Environmental reporting: toward enhanced information quality. Business Horizons. v. 54, p. 425-433, 2011.

RAUPP, Fabiano Maury. BEUREN, Ilse Maria. Caracterização da Pesquisa em Contabilidade. In. BEUREN, Ilse Maria (Org). Como elaborar trabalhos monográficos em contabilidade: teoria e prática. 3. ed. São Paulo: Atlas, 2008.

REZENDE, I. A. C.; SANTOS, L. S. R. Análise da Rentabilidade e Performance dos Investimentos Socialmente Responsáveis: um estudo empírico no mercado brasileiro. In: Encontro da Associação Nacional de Pós-Graduação e Pesquisa em Administração, 30., 2006, Salvador. Anais... Salvador: EnANPAD, 2006. CD-ROM.

RIBEIRO, Maisa de Souza. O Custeio por Atividades Aplicado ao Tratamento 
Contábil dos Gastos de Natureza Ambiental. Caderno de Estudos, São Paulo, FIPECAFI, v.10, n.19, p.82-91, set/dez 1998.

RIBEIRO, Maisa de Souza. Contabilidade ambiental. São Paulo: Saraiva: 2005.

RICHARDSON, Roberto Jarry. Pesquisa Social: métodos e técnicas. 2. ed. São Paulo: Atlas, 1989.

ROVER, Suliani; BORBA, José Alonso; BORGERT, Altair. Como as Empresas Classificadas no Índice de Sustentabilidade Empresarial (ISE) Evidenciam os Custos e Investimentos Ambientais? Revista de Custos e @gronegócio online . v.4, n. $1-$ jan/abr -2008.

ROVER, Suliani et al. Explicações para a divulgação voluntária ambiental no Brasil utilizando análise de regressão em painel. In: Congresso Associação Nacional dos Programas de Pós-Graduação em Ciências Contábeis, 3., 2009, São Paulo. Anais... São Paulo: ANPCONT, 2009. CD-ROM.

SOUZA, Valdiva R.; RIBEIRO, Maisa de S. Aplicação da contabilidade ambiental na indústria madeireira. Revista de Contabilidade \& Finanças - USP. São Paulo, n. 35, p. 54-67, 2004.

TINOCO, João Eduardo Prudêncio; KRAEMER, Maria Elisabeth Pereira. Contabilidade e gestão ambiental. São Paulo: Atlas, 2004.

TRIVIÑOS, A. N. S. Introdução à pesquisa em ciências sociais: a pesquisa qualitativa em educação. São Paulo: Atlas, 1987. 175 p.

VAZ, A. C.; et al. Análise comparativa sobre informações voluntárias divulgadas: o social disclosure das empresas latino-americanas listadas na Nyse. In: Encontro da Associação Nacional de Pós-Graduação e Pesquisa em Administração, 32., 2008, Rio de Janeiro. Anais... Rio de Janeiro: ANPAD, 2008. CD-ROM.

VILLIERS, Charl de.; VAN STADEN, Chris J. Shareholder's requirements for corporate environmental disclosures: a cross country comparison. The British Accounting Review. v. 42, p. 227-240, 2010. 